\title{
Espaços de Saúde e Cultura: experiência do Fórum Social Mundial às Tendas de Educação Popular em Saúde
}

Thaís Maranhão(a)

Osvaldo Peralta Bonetti ${ }^{(b)}$

Vanderleia Laodete Pulga Daron ${ }^{(c)}$

Odete Messa Torres ${ }^{(d)}$

Maranhão T, Bonetti OP, Daron VLP, Torres OM. Spaces of Health and Culture: the experience of the World Social Forum and the Tents of Popular Education in Health. Interface (Botucatu). 2014;18 Supl 2:1175-1186.

In order to identify possible contributions to the field of public health, the article analyzes the Spaces of Health and Culture offered in the World Social Forums that were held in Brazil. It is a qualitative research with a descriptive approach that used documents, reports, videos and notes registered in a field diary. The results indicate that the Spaces of Health and Culture innovated by enabling interactions among several public health actors, articulated with the Movement of Popular Health Education, health workers, managers and youth movements. Popular Education was mentioned as the political-methodological framework of the formulation of the spaces, which potentialized the construction of a multicultural network with the proposition of new ways to produce health. "Che Space" was the source of inspiration for the Paulo Freire Tents, held in events of the area, scientific conferences, meetings and seminars.

Keywords: Popular Education Health. Community participation. Public health.
Na busca de identificar possíveis contribuições para o campo da saúde coletiva, o artigo analisa os Espaços de Saúde e Cultura realizados nos Fóruns Sociais Mundiais no Brasil. Trata-se de pesquisa qualitativa, de abordagem descritiva, com uso de pesquisa documental, utilizando documentos, relatórios, vídeos e anotações em diário de campo. Os resultados apontam que os Espaços de Saúde e Cultura inovaram ao aproximar diversos atores da saúde coletiva, articulados ao Movimento de Educação Popular em Saúde, trabalhadores da saúde, gestores e movimentos de juventude. A Educação Popular é apontada como referencial político-metodológico da formulação dos espaços, os quais potencializaram a construção de rede multicultural com proposição de novas formas de produzir saúde. Afirma-se o "Espaço Che" como fonte de inspiração para as Tendas Paulo Freire, realizadas em eventos da área, congressos científicos, encontros e seminários.

Palavras-chave: Educação Popular em Saúde. Participação comunitária. Saúde Coletiva.

\footnotetext{
Pós-Graduaçăograma de Coletiva, Universidade Federal do Rio Grande do Sul. Rua Joaquim Nabuco, 90, Cidade Baixa. Porto Alegre, RS, Brasil. 90050-340. Bolsista Fapergs. maranhao. thais@gmail.com (b) Departamento de Gestão Participativa, Comitê Nacional de Educação Popular em Saúde, Secretaria de Gestão Estratégica e Participativa, Ministério da Saúde. Brasília, DF, Brasil. obonettibr@yahoo.com.br (c) Componente Curricular de Saúde Coletiva, curso de graduação em Medicina,

Universidade Federal da Fronteira Sul, campus Passo Fundo. Passo Fundo, RS, Brasil. vanderleia.daron@gmail.

(d) Curso de Enfermagem, Universidade Federal do Pampa. Uruguaiana, RS, Brasil.

odetetorres@gmail.com
} 


\section{Convite aos Espaços de Saúde e Cultura}

A formulação dos Espaços de Saúde e Cultura (ESCs) partiu da inquietação dos atores dos movimentos de juventude e dos movimentos populares de saúde, envolvidos com a realização do Fórum Social Mundial (FSM) e do Acampamento Intercontinental da Juventude (AIJ), em Porto Alegre (RS), no ano de 2005, ao identificarem a necessidade de aprofundar o debate e elaborar alternativas em contraponto às políticas neoliberais e seus impactos sobre a saúde dos povos.

No contexto do FSM, optar por construir ESCs nos AIJs, configurados em "territórios das práticas", expressou o desejo de construir um local de compartilhamento de práticas de Educação Popular em Saúde (EPS), em especial as práticas populares de cuidado, oportunizando também discussões e mobilização em relação à saúde entre o público participante do FSM.

Além de lócus do debate sobre as questões relacionadas com a saúde, os ESCs configuraramse em local físico de referência para o cuidado em saúde dos participantes do FSM e conquistaram valor simbólico entre aqueles que defendem uma concepção de saúde humanizada e integralizadora, respeitosa com a biodiversidade e em diálogo com a saúde dos povos.

Este texto apresenta um breve registro histórico dos ESCs, na expectativa de contribuir para a superação da carência de sistematizações e publicações sobre essas experiências. A reflexão sobre os ESCs ganha relevo no momento atual, no qual vivenciamos a institucionalização de uma Política Nacional de Educação Popular em Saúde no Sistema Único de Saúde - PNEP-SUS'. Processo este que tem fomentado novas falas, práticas, espaços e reflexões com base na concepção político-pedagógica da EPS.

\section{Caminhos metodológicos}

Estudo de natureza qualitativa, exploratório e descritivo. Desenvolvido com coleta de dados mediante pesquisa documental retrospectiva.

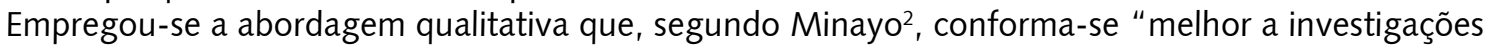
de grupos e segmentos delimitados e focalizados, de histórias sociais sob a ótica dos atores, de relações e para análises de discursos e de documentos" (p. 57).

A fase exploratória da pesquisa permite resgatar processos mediante pesquisa documental, compreende as etapas de escolha do tópico de investigação, de delimitação do problema, de definição do objeto e dos objetivos, de construção do marco teórico conceitual, dos instrumentos de coleta de dados e da exploração do campo². Por sua vez, a fase descritiva da pesquisa permite conhecer um fenômeno em uma determinada realidade de modo aprofundado ${ }^{3,4}$.

Segundo Laperiére ${ }^{5}$, para melhor conhecer a realidade contemporânea da Educação Popular, uma pesquisa necessita aproximar-se do campo de atuação dos movimentos sociais, das organizações populares da sociedade civil e das novas políticas sociais comprometidas com a ampliação da participação popular.

Os autores desta pesquisa protagonizaram a construção dos ESCs, o seu planejamento e execução, desde sua primeira edição. Provenientes de diferentes espaços de participação, como movimento estudantil e gestão, tiveram a militância do movimento popular de saúde como ponto de articulação. Cabe referir que, durante o percurso histórico de realização dos ESCs, tais atores mudaram seus espaços de atuação, a exemplo dos que, na primeira vivência, faziam parte do movimento estudantil da área da saúde e posteriormente ocuparam os espaços da gestão, atenção e da formação acadêmica em saúde quando inseridos no mundo do trabalho.

Nesse sentido, o campo de investigação deste estudo buscou se delinear em materiais empíricos e analíticos, resgatando-se registros históricos sobre os ESCs, sendo utilizados, tanto documentos oficiais (projetos, termos de referências e vídeos), como também textos e produções informais dos autores desta pesquisa, protagonistas dos Espaços, mediante seus relatos de experiência e registros em diário de campo.

A vivência consecutiva nos ESCs trouxe inquietações e reflexões que suscitaram a elaboração desta pesquisa com o objetivo de colaborar com a sistematização dos ESCs, procurando identificar seus desdobramentos e contribuições para a saúde coletiva. 
Durante a etapa de pesquisa documental, buscou-se referenciais que contribuíssem com o aprofundamento conceitual acerca dos eixos transversais da experiência, utilizando-se como termos a Educação Popular em Saúde e o Fórum Social Mundial.

A análise dos dados seguiu as etapas de análise de conteúdo propostas por Minayo², quer sejam: (1) Ordenação dos dados; (2) Classificação; e, (3) Análise. As categorias de análise eleitas possibilitaram como resultados: (1) O contexto para a construção do Espaço de Saúde e Cultura; (2) O "Espaço Che" - a saúde tecendo redes no Fórum Social Mundial; (3) A Educação Popular em Saúde como referencial dos Espaços de Saúde e Cultura; (4) Aprendizados para produção de saúde a partir dos Espaços de Saúde e Cultura.

\section{O contexto para a construção do Espaço de Saúde e Cultura}

A ideia de criar o Fórum Social Mundial, segundo Cassen ${ }^{6}$, foi de suscitar reação ao Fórum Econômico Mundial, realizado anualmente na cidade de Davos na Suíça. Nessa perspectiva, a similaridade do nome aproveita o caráter midiático mobilizado pelo Fórum Econômico para publicizar a contraposição ideológica, inserindo o interesse popular na pauta mundial. Da mesma forma contrahegemônica, o local de realização do FSM foi pensado de modo a romper geográfica e simbolicamente com qualquer equívoca associação ideológica com o fórum de Davos, por isso, foi proposto em território que possuísse governo identificado com o campo democrático e popular.

Assim, trocou-se o foco da reflexão sobre o novo modelo de organização internacional centrada na perspectiva econômica para a social, demonstrando que a melhoria da qualidade de vida no mundo será conquistada por meio de redes de solidariedade, permeadas por valores humanitários e democráticos, e não pela via do capital.

$\mathrm{Na}$ Carta de Princípios do $\mathrm{FSM}^{7}$, ficam explícitas suas características, dentre elas: ser um espaço plural e diversificado, não governamental, não confessional, de articulação, de troca de experiências entre entidades e movimentos que combatem o neoliberalismo e o domínio do mundo pelo capital e qualquer forma de imperialismo. Ao utilizar a insígnia que virou sua marca registrada, pode-se dizer que o FSM é mais que um evento, é um movimento mundial, articulador de atores, movimentos e redes, estimulador do debate e da busca de alternativas concretas para a construção de "um outro mundo possível"8 (p. 8).

Para Santos ${ }^{8}$, o FSM mostra-se como um fenômeno social e político novo, apesar de várias de suas características não serem novidade. O autor destaca que a novidade do FSM é o fato de ser inclusivo e global na forma como agrega os movimentos, sejam locais, nacionais ou globais, "[...] 'o movimento dos movimentos', não apenas mais um movimento"8 (p. 7).

Contudo, segundo Grzybowski ${ }^{9}$, a força do FSM é o fato de querer tornar-se um grande movimento de ideias, que se alimenta na diversidade de possibilidades humanas, opondo-se ao pensamento único dominante. Assim, o FSM surge como proposta fortalecedora do movimento internacional de resistência à globalização neoliberal, que se tornara hegemônica nas últimas décadas.

Juntamente com o surgimento do FSM, organizou-se um espaço de vivência, proposto pela juventude: o Acampamento Intercontinental da Juventude (AIJ). Os AIJs foram realizados durante os Fóruns no Brasil, nas edições de 2001, 2002, 2003, 2005, 2009 e 2010, e ficaram conhecidos como "laboratórios de conhecimentos" ou "território das práticas"10 (p. 16). Isso por se constituírem em espaços de debates e ações de forma a apresentar alternativas ao pensamento hegemônico imposto à ciência pelo modelo capitalista e explícito nos múltiplos campos da vida social. Foram protagonizados pela juventude que buscava, além de uma hospedagem mais solidária, também exercitar outras formas de convívio em sociedade, por meio da autogestão, da economia solidária, da alimentação ecológica, da liberdade de expressão, entre outros aspectos.

No Brasil, merece destaque o ano de 2003, por este ter sido marcado por intensa mobilização popular, na qual movimentos sociais e populares, universidades, intelectuais orgânicos e entidades civis 
apresentavam-se engajados na construção de mudanças nas políticas públicas a partir do governo de Luís Inácio Lula da Silva.

Segundo Sader ${ }^{11}$, Lula pode ser considerado uma expressão da esquerda por suas políticas sociais, pelo bloqueio à Alca e pela prioridade dada aos processos de integração regional e Sul-Sul, por ter freado as privatizações e os processos de enfraquecimento da capacidade de intervenção do Estado e de precarização das relações de trabalho, assim como, por ter aumentado sistematicamente o emprego formal, diminuindo o desemprego e elevado o poder aquisitivo do salário mínimo ${ }^{11}$.

No campo das políticas públicas no setor saúde, destacamos que houve diversas inovações, especialmente relacionadas às mudanças na formação e do trabalho em saúde, desencadeadas a partir da criação da Secretaria de Gestão do Trabalho e da Educação em Saúde (SGTES) no Ministério da Saúde. Ações estas articuladas a então inaugurada Política Nacional de Educação Permanente em Saúde ${ }^{12,13}$ e também à incorporação da Educação Popular em Saúde como política pública por meio da criação de uma Coordenação Geral de Apoio à Educação Popular e Mobilização Social na SGTES ${ }^{14}$.

Dessa forma, ocorreu um significativo fomento às articulações dos movimentos populares de saúde, do movimento estudantil, das associações de ensino, dentre outros. Buscou-se estimular a auto-organização desses movimentos, tendo o protagonismo da juventude como um referencial de destaque, bem como a participação popular na construção e implementação das políticas públicas de saúde, fortalecendo princípios de uma gestão participativa no setor. Assim, vivenciou-se à época o crescimento do movimento estudantil no campo da saúde e a intensificação do protagonismo dos movimentos populares na defesa do SUS'1.

Nesse cenário, foi concebida a Articulação Nacional de Movimentos e Práticas de Educação Popular em Saúde (Aneps), que surgiu com o objetivo de articular e apoiar os movimentos e as práticas de Educação Popular em Saúde, desenvolver processos formativos e reflexivos a partir da práxis, além de construir referências para a formulação de políticas públicas.

A Aneps foi constituída por múltiplos movimentos do campo e da cidade. Dentre eles, a Rede de Educação Popular e Saúde (RedePop), o Movimento dos Trabalhadores Sem Terra (MST), o Movimento Popular de Saúde (Mops), a Direção Executiva Nacional dos Estudantes de Medicina (Denem), a Executiva Nacional dos Estudantes de Enfermagem (ENEEnf), o Movimento das Mulheres Camponesas (MMC), o Movimento de Reintegração dos Atingidos pela Hanseníase (Morhan) e o Projeto Saúde e Alegria ${ }^{15}$.

Outro fato importante, no contexto de 2003, foi a ação mobilizada pelo campo governamental em conjunto com o movimento estudantil da área da saúde, intitulada Projeto Vivências e Estágios na Realidade do Sistema Único de Saúde (VER-SUS). Esse projeto proporcionou a vivência de estudantes nos espaços de gestão, educação, atenção e controle social em saúde, aproximando a formação multiprofissional e interinstitucional da prática cotidiana da gestão das políticas de saúde, da gestão dos serviços, e do cuidado no âmbito do SUS ${ }^{16}$.

Com caráter formativo, no sentido de proporcionar aos estudantes conhecer o SUS, soma-se o caráter político, na busca de aproximar os estudantes universitários ao movimento estudantil organizado. A mobilização para a luta pela consolidação do SUS e para mudanças na formação profissional na área da saúde apresentam-se como uma perspectiva transversal da experiência, sendo o protagonismo estudantil a sua marca ${ }^{17}$.

O momento político, do início do século XXI, mostrou-se um importante período de mudanças nas políticas públicas brasileiras e de efervescência de movimentos sociais. Pode-se dizer que é notória a identidade ideológica da Educação Popular com o ideário do FSM, visto que a própria critica à sociedade neoliberal é explícita na produção teórica derivada desse campo, a exemplo da obra de Paulo Freire ${ }^{18}$ que afirmava ser radicalmente "[...] contra a ordem capitalista vigente que inventou esta aberração: a miséria na fartura" (p. 64).

Embora a participação de atores referenciados na EPS nos FSM ocorra desde o primeiro Fórum, em 2001, assim como, a problematização sobre os reflexos negativos do sistema capitalista na saúde dos povos seja algo bastante exercitado na produção teórica do campo, podemos afirmar, que a participação organizada, enquanto coletivo, inicia-se no ano de 2003. Neste ano, atores do campo da EPS realizaram uma oficina de três dias, articulados ao Grupo de Trabalho de Educação Popular e Saúde 
da Associação Brasileira de Pós-Graduação em Saúde Coletiva (GT de EPS da Abrasco), à Rede de Educação Popular e Saúde e à Escola de Saúde Pública do Rio Grande do Sul (ESP/RS).

A oficina pode ser considerada como a primeira atividade organizada colegiadamente por atores do campo da Educação Popular em Saúde. Sua realização fortaleceu a pauta trazida pelo FSM na agenda política da EPS e possibilitou a construção dos ESCs que sucederam ao FSM de 2001 e inspiraram a construção de outros ESCS, como as Tendas Paulo Freire ${ }^{19,20}$.

\section{O "Espaço Che" - a saúde tecendo redes no Fórum Social Mundial}

O primeiro Espaço de Saúde e Cultura (ESC) - nomeado Ernesto Che Guevara - aconteceu no Acampamento Intercontinental da Juventude (AIJ) do FSM de 2005, decorrente da organização da primeira Comissão de Saúde, em AIJ, que apresentava como objetivos: construir um centro articulador de ações para "implementar uma rede de cuidados" de assistência e a promoção à saúde dos acampados; dar visibilidade a movimentos e práticas populares em saúde no sentido de se constituir num "local onde a resistência está colocada como uma prerrogativa política, um laboratório prático e provocador da reflexão sobre as experiências de EPS nele propostas" (p. 7); assim como a realização de debates sobre saúde no contexto de globalização neoliberal ${ }^{21}$.

O "Espaço Che" incorporou uma das ideias principais dos AlJ ao constituir-se como "laboratório de práticas", uma vez que atrelou o desafio de promover o cuidado em saúde dos acampados do AIJ e participantes do FSM de forma contra-hegemônica, resgatando o saber popular no jeito de promover e fazer saúde. Constitui-se em espaço de debate, no qual foram desenvolvidas rodas de conversa, oficinas, expressões da arte e da cultura populares no campo da saúde ${ }^{21,22}$.

O "Espaço Che" foi idealizado e construído num contexto de efervescência dos movimentos de juventude da área da saúde - representados pelo movimento estudantil e de residentes - e dos movimentos ligados à Educação Popular em Saúde, representados principalmente pela Aneps, agregando novos atores que até então atuavam de forma desarticulada em diversos ambientes/ segmentos como o do trabalho, da gestão e dos usuários, nesse caso, os acampados.

De certa forma, os encontros e processos desencadeados pelas políticas e ações conquistadas ao nível de Governo Federal em 2003, anteriormente citadas, e a articulação de movimentos sociais na saúde, potencializaram a inauguração da primeira Comissão de Saúde no AlJ do FSM de 2005, consequentemente a realização do "Espaço Che".

Essa Comissão, resgatada por meio do projeto da Comissão de Saúde do AlJ e de registro em diário de campo dos autores deste relato, foi composta por aproximadamente cinquenta voluntários, dentre eles profissionais e estudantes da área da saúde e educação, destacando-se o engajamento da Executiva Nacional de Estudantes de Enfermagem (ENEEnf) e de representantes de movimentos populares como o Movimento dos Trabalhadores Sem Terra (MST), o Movimento das Mulheres Camponesas (MMC), o Movimento de Luta pela Moradia (MLM), a Central de Movimentos Populares (CMP), Maria Mulher, dentre outros, mobilizados pela Articulação Nacional de Movimentos e Práticas de Educação Popular em Saúde.

Esses atores coletivos trabalharam no sentido de fomentar o engajamento da juventude na construção da Educação Popular em Saúde como uma política pública, acreditando que o debate e a luta pelo direito à saúde deveriam ser mais difundidos e reforçados nas comunidades, nos centros formadores e nos movimentos sociais.

Durante a preparação do AIJ, em 2005, além da Comissão sediada em Porto Alegre, existiram comissões locais em São Paulo e Salvador. Estabeleceu-se uma rede virtual que fez com que a Comissão fosse ampliada para além da participação presencial22.

Nos dias de acampamento, os atores dos outros estados estavam presentes, trabalhando diretamente no "Espaço Che", tanto nos atendimentos realizados na sala de procedimentos, quanto na farmácia verde, na massoterapia, no Reiki e no trabalho de campo. À medida que as pessoas chegavam 
ao AIJ, integravam-se ao trabalho, em virtude de estarem afinadas e terem contribuído em sua construção.

Cabe referir que o Ministério da Saúde, por meio da SGETS, apoiou a iniciativa, por meio de investimento político e financeiro, vindo a custear a estrutura do Espaço e o deslocamento de 11 ônibus, nos quais foram transportados ao $5^{\circ} \mathrm{AlJ}$ em torno de quatrocentos atores, de diversas partes do país, oriundos de movimentos sociais, do movimento estudantil e profissionais da área da saúde, engajados na construção de outro jeito de fazer saúde. Esses foram articulados por meio das Aneps estaduais, com auxílio da Comissão de Saúde de Porto Alegre(e).

A estrutura do Espaço foi construída pelos próprios membros da Comissão de Saúde, orientados por voluntários do movimento de permacultura, tendo um espaço de $160 \mathrm{~m}^{2}$ de área construída em formato em espiral, trazendo a simbologia dessa forma, culturalmente associada ao equilíbrio e a integralidade, representando a evolução e busca pela saúde, e uma cobertura em formato circular de aproximadamente $400 \mathrm{~m}^{2}$, a qual abrigava uma Farmácia Verde (construída em parceria com atores do Movimento dos Trabalhadores Sem Terra) e espaço para rodas de conversa, oficinas e demais atividades. Ainda, de forma articulada ao "Espaço Che", foi construído o Espaço Criança, ou Acampadinhos, como ficou conhecido, buscando contribuir com o acolhimento e cuidado das crianças filhas dos participantes do FSM(e).

O processo de trabalho da Comissão de Saúde foi pautado pelos princípios da EPS, buscando fomentar o protagonismo coletivo na tomada de decisão que possibilitava a autogestão das ações cotidianas. As decisões e encaminhamentos a respeito da Comissão de Saúde eram feitas no grande coletivo, por meio de periódicas reuniões e assembleias realizadas antes, durante e depois dos trabalhos no acampamento.

Bonetti e Cariri(e), articuladores da Comissão, ao refletirem sobre a organização desse acampamento, apontam que a participação popular era uma característica orgânica das práticas desenvolvidas no "Espaço Che" e não uma prática isolada que tivesse um dia ou horários delimitados para acontecer. Os usuários (acampados) eram convidados a participar de todos os processos, inclusive a gestão do espaço físico, do cuidado e da produção de conhecimento.

Um aspecto interessante para o qual esses autores chamam a atenção é que, embora houvesse consenso entre aqueles envolvidos na organização do espaço, a exemplo da defesa do respeito à diversidade de saberes como um princípio das ações e práticas desenvolvidas, o diálogo e construção compartilhada não foram fáceis de serem vivenciados. Afirmam que os conflitos foram inerentes ao processo desde sua formulação até o momento da realização do cuidado durante os dias de FSM.

Em momentos diferentes, conhecimentos técnico-científicos e populares entravam em choque e desafiavam os participantes na construção da solução para determinado problema. Para ilustrar, trazem como exemplo ocasiões em que estudantes, profissionais de saúde e cuidadores populares tinham de definir a terapêutica para determinada situação de saúde, na qual deveriam decidir se usariam um medicamento alopático ou remédio natural. Problematização que gerava debate não apenas acerca da efetividade terapêutica, como também sobre geração de autonomia na produção da saúde ${ }^{22}$. Muitas vezes, práticas coexistiram, somando esforços terapêuticos em prol da atenção em saúde, como afirma uma entrevistada no vídeo ${ }^{21}$ "malva é aqui e benzetacil é ali".

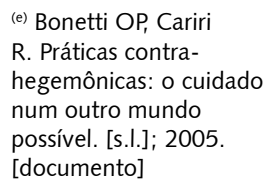


As atividades realizadas no "Espaço Che" foram selecionadas pela Comissão de Saúde após o encerramento das inscrições de atividades no site do FSM. A partir da seleção dessas atividades, a Comissão iniciou um trabalho de articulação com os responsáveis por cada uma das mais de cem atividades selecionadas, a fim de apresentar de forma mais dialogada a proposta do Espaço e sua perspectiva metodológica, como também, buscando congregar atividades com identidade temática. Logo, a vivência do Espaço Che propiciou a articulação de movimentos de diversas naturezas e bandeiras de luta, fortalecendo o trabalho já em curso desenvolvido pela Aneps.

O princípio transversal, que garantiu a convergência dessa multiplicidade de atores, consistia no diálogo entre o saber popular e o saber científico e na legitimidade das ações e práticas oriundas dessa articulação, proporcionando vivências de modos de produção de saúde baseados na solidariedade, no amor e no respeito às diferentes culturas e formas de "andar a vida" dos participantes.

Após essa experiência, foram realizados ainda outros dois Espaços de Saúde e Cultura em Acampamentos Intercontinentais da Juventude, sendo eles: o "Espaço Pai D'Égua" em Belém-PA, em 200923, e o "Espaço Mercedes Sosa" em Novo Hamburgo, em 2010. Nesse sentido de experiência, houve ainda o "Espaço Piracema", no Acampamento Binacional da Juventude do Fórum Binacional Brasil-Uruguai, ocorrido na Barra do Chuí no ano de 2006.

Ao analisar o percurso histórico dos movimentos referenciados na Educação Popular em Saúde desde o FSM de 2005, é possível afirmar que a realização do "Espaço Che" potencializou o ideário de que "uma outra saúde é possível"8 (p. 8). A possibilidade de vivenciar o jeito popular de fazer saúde, aliando saberes e valorizando o saber popular no cuidado em saúde, foi a tônica para que a experiência do "Espaço Che" não tivesse ficado restrita aos AlJs e sim, tenha se espalhado pelo país, ao inspirar novos espaços de participação popular no âmbito da saúde, como as Tendas de Educação Popular em Saúde Paulo Freire ${ }^{18}$. Ao se referir às tendas, Oliveira ${ }^{20}$ (p. 305) afirma que "esta atividade teve sua inspiração no 'Espaço Che', realizado no Fórum Social Mundial de 2005, em Porto Alegre, onde se desenvolveu ações e reflexões sobre saúde na perspectiva popular em diálogo com a perspectiva acadêmica".

As Tendas têm trazido uma grande contribuição social, política e metodológica aos eventos da área. Pode-se afirmar que sua dinâmica de formulação e as metodologias empregadas em sua realização como as rodas de conversa, o túnel de cuidados, o espaço para as práticas populares de cuidado, os círculos de cultura e diversas expressões da arte e cultura popular - têm fomentado o protagonismo do saber popular nos espaços de construção do conhecimento da área da saúde. Da mesma forma, têm contribuído com a mobilização popular pelo direito à saúde, sendo organizadas na perspectiva da inclusão dos atores populares, desde sua construção, perpassando o debate científico e acadêmico, que oficializam e estruturam saberes no setor saúde.

As Tendas Paulo Freire possibilitam a inserção mais expressiva da Educação Popular no SUS, por meio da agenda política construída nos congressos e eventos da área da saúde, possibilitando o diálogo com a diversidade de atores implicados com o Sistema, como gestores, trabalhadores, acadêmicos e usuários. Apresentaram-se como espaços estratégicos para a formulação da PNEP-SUS, recentemente aprovada ${ }^{1}$.

Observa-se também, inspirados nas experiências relatadas, a inauguração de espaços permanentes como o Espaço Ekobé, no Ceará, construído no campus da Universidade Estadual do Ceará, e o Espaço de Vivência em Sergipe. São espaços que apresentam arquiteturas inspiradas na permacultura e têm como objetivo principal promover o intercâmbio e o encontro entre saberes, potencializando um jeito popular de cuidar a saúde.

\section{A Educação Popular em Saúde como referencial dos Espaços de Saúde e Cultura}

A Educação Popular e Saúde configurou-se como o principal referencial político-metodológico dos ESCs. Ela incorpora e reflete o conhecimento adquirido na prática cotidiana das pessoas, valorizando a experiência vivida dos sujeitos, referenciando-se no diálogo entre a diversidade de saberes, garantindo 
a legitimidade do saber popular diante do saber técnico-acadêmico e destacando sua potencialidade para a transformação da realidade excludente.

Sua perspectiva dialógica põe em cheque certezas absoluta e, ao apresentar a problematização como ponto de partida para toda reflexão e ação, que busque impacto e efetividade na vida das pessoas, suscita novas perguntas para serem respondidas coletivamente. Assim, ao analisar a realidade cotidiana, os indivíduos são instigados a identificar suas situações limites e mobilizar suas potencialidades no caminho do inédito viável ${ }^{24}$.

Tal proposta encontra identidade com Santos ${ }^{24}$. O autor afirma que o saber só existe enquanto diversidade de saberes existentes no mundo e defende como uma exigência atual identificar e colocar tais saberes em comparação no sentido de que os indivíduos rompam fronteiras e construam saberes mais integrais, que atendam com mais efetividade os problemas do nosso tempo.

Contribuindo com essa afirmativa, Vasconcellos ${ }^{25}$ declara que a EPS amplia o espaço de interação cultural e negociação dos sujeitos envolvidos em um determinado problema social, no sentido de organizar o conhecimento e uma política para sua superação. Já Valla ${ }^{26}$, aponta que a Educação Popular é a indicação de problemas concretos e o esforço de resolvê-los.

Ribeiro ${ }^{27}$ registra que não há acordo na delimitação do conceito de Educação Popular por conta da variedade de práticas que a aplicam. Entretanto, propõe que um aspecto em comum é a questão de classe. Para a autora, a Educação Popular não atende às classes que detêm o poder econômico-político.

A EPS é também um compromisso político com as classes populares, com a luta por melhores condições de vida e de saúde, pela cidadania e pelo controle social. Está diretamente ligada à valorização e à construção da participação popular. Tem uma perspectiva histórica, reconhecendo os pequenos passos e os movimentos das forças sociais em busca do controle de seu próprio destino ${ }^{27}$.

Stotz ${ }^{28}$ afirma que a EPS tem se apresentado como um contraponto às práticas centralizadas e autoritárias que ainda demarcam a gestão, o cuidado e as ações transversais da educação e saúde.

Segundo Pedrosa ${ }^{29}$, a Educação Popular em Saúde representa a conjunção de conceitos polissêmicos em suas significações, mas que ganham expressões concretas nas ações dos sujeitos sociais orientadas pela construção de vínculos afetivos, sociais e político-ideológicos com as camadas populares, promovendo a vivência coletiva em torno de movimentos que levam a projetos de emancipação, libertação, autonomia, solidariedade, justiça e equidade.

Vasconcelos ${ }^{25}$ define Educação Popular como um modo de participação para a organização de um trabalho político que abra caminho para a conquista da liberdade e de direitos. Objetiva trabalhar pedagogicamente o homem e os grupos envolvidos no processo de participação popular, fomentando formas coletivas de aprendizado e investigação, de modo a promover o crescimento da capacidade de análise crítica sobre a realidade e o aperfeiçoamento das estratégias de luta e enfrentamento. Segundo o autor, a Educação Popular não é veneração da cultura popular, mas, modos de sentir, pensar e agir que interajam permanentemente com outros modos diferentes de sentir, pensar e agir.

Assim, a diversidade e a promoção da troca entre culturas e saberes é elemento fundamental da democratização dos processos educativos. Contrapondo-se a uma cultura sanitária conservadora, percebe-se a configuração de novos espaços de participação popular sendo gestados no contexto do SUS, fortalecendo essas contradições. Nesse processo contra hegemônico, constituem-se as novas redes de movimentos e práticas de Educação Popular em Saúde.

\section{Aprendizados para produção de saúde a partir dos Espaços de Saúde e Cultura}

Os ESCs proporcionaram experiências inovadoras para o campo da saúde coletiva ao apresentar uma práxis transformadora no caminho de uma saúde integral, cuidadora e emancipatória. Assim como explicitou as contradições entre um novo modo de produzir saúde em contraponto ao modo de vida imposto pela sociedade capitalista.

$\mathrm{Na}$ busca para contribuir com a sistematização da multiplicidade de princípios agregados à realização dos ESCs, resultado das categorias analisadas neste estudo, apresentam-se em dimensões 
organizadas: (1) democrática e participativa, (2) política, (3) educativa e emancipatória, (3) acolhedora, afetiva e espiritual, (4) artística-cultural e (5) cuidadora. Essas dimensões são fruto da análise de conteúdo realizada neste estudo, a partir da pluralidade de materiais que retomam as experiências dos participantes que tornaram os ESCs uma referência nacional para a construção de uma nova forma de produção de saúde.

A dimensão democrática e participativa refere-se à forma de relação entre as pessoas que participavam do espaço e da pluralidade de formas de pensar e praticar saúde. Não havia diferenciação entre organizadores e participantes, todos protagonizavam a realização dos debates e das práticas. A dimensão democrática valorizou a polifonia expressa pela diversidade dos atores, dos movimentos e dos conhecimentos compartilhados.

A dimensão política aponta que a transformação da realidade deve considerar a experiência acumulada historicamente pelos sujeitos populares e movimentos sociais no enfrentamento das situações-limite cotidianamente vivenciadas. Os Espaços configuraram-se locais de articulação de movimentos sociais, trabalhadores, atores da academia e até gestores para lutas contra-hegemônicas que produzissem novas formas de fazer saúde e construir o SUS. Possibilitaram a visibilidade da Educação Popular em Saúde no diálogo com os diversos atores que compõem o SUS para apoio político e estratégico de disseminação das experiências.

A dimensão educativa e emancipatória consistiu no aprendizado pela troca de experiências e construção coletiva de saberes e práticas, tal como na perspectiva de construção de projetos coletivos de transformação social. Os ESCs contribuíram para o empoderamento de atores e movimentos sociais, organizados em prol da defesa de "uma outra saúde possível"8.

A dimensão acolhedora, afetiva e espiritual foi construída a partir da valorização de outras racionalidades no cuidado e no fazer saúde de modo geral, para além daquelas legitimadas pelo saber convencional que nem sempre estão ao alcance da apreensão do conhecimento técnico-científico.

A dimensão artística e cultural evidenciou-se nas múltiplas manifestações artísticas e culturais no espaço, com participação nas rodas de conversa. Incluiu-se também a visibilidade das práticas tradicionais de cuidado, valorizando o conhecimento popular e sua historicidade.

A dimensão cuidadora talvez tenha sido a que ficou mais evidenciada entre aquelas que dialogaram com os ESCs, ofertando o contato e a visibilidade às múltiplas práticas de cuidado, relacionadas com as diversas racionalidades que compõem, e outras que extrapolam o campo da saúde coletiva.

Enfim, essas dimensões não podem ser isoladas para a compreensão dos propósitos dos ESCs, estão imbricadas e coexistem nesses novos territórios de produção de sujeitos e de saúde.

Este ensaio possibilitou identificar a potencialidade que o "Espaço Che" trouxe ao movimento de EPS, possibilitando afirmar que esse precursor dos ESCs inspirou a inserção das Tendas no setor saúde, inaugurando um novo jeito de participar e promover saúde no cenário de construção do saber no SUS, mais identificados com a cultura popular, acolhendo atores até então invisibilizados nesse contexto.

As contribuições dos ESCs aos espaços instituídos no campo da saúde, como eventos científicos, congressos e seminários, ainda estão em fase de conformação, não causando mais estranhamento. $\mathrm{Na}$ atualidade, os ESCs estão compondo as comissões próprias desses eventos, sinalizando a ressignificação dos modos de compreender, ser e fazer saúde no meio acadêmico. O desafio aqui colocado volta-se à inserção desses ESCs em espaços formais de ensino das profissões da saúde, provocando a necessária mudança na graduação com vistas que a Educação Popular em Saúde transversalize a formação acadêmica.

Os ESCs configuram-se em dispositivos potentes para muitas mudanças na saúde coletiva e deverão ser referência político-metodológica para implementação dos Centros de Educação Popular em Saúde hoje expressos no Plano Operativo da Política Nacional de Educação Popular e Saúde 1 . Esse novo jeito de promover e produzir saúde poderá contribuir com a busca da mudança do modelo de atenção à saúde e trazer uma nova estética para o SUS, inquietando o modelo da formação profissional e da organização dos serviços de saúde articulados no SUS.

Os princípios da EPS, como a afetividade, o diálogo e a articulação entre saberes técnico-científicos e populares, apresentam-se estratégicos para o campo da saúde coletiva na atualidade, fortalecendo o imperativo ético para a sociedade atual na construção de uma verdadeira ecologia dos saberes ${ }^{25}$. 
Verifica-se que os ESCs conseguiram unir a crítica ao pensamento único imposto pelo neoliberalismo e fomentar o aparecimento de práticas contra hegemônicas do jeito de cuidar e participar no setor saúde, fomentando o engajamento e a criatividade da juventude na luta pelo direito à saúde e transformando espaços instituídos de fazer e produzir conhecimento em saúde. Evidencia-se, a importância do conceito da polifonia na saúde, mostrando que a construção deve ser coletiva, plural, inclusiva, dialógica e democrática e que essa mistura tem o potencial de produzir inovações epistemológicas.

\section{Colaboradores}

Thaís Maranhão, Osvaldo Peralta Bonetti e Vanderleia Laodete Pulga Daron participaram igualmente da elaboração do artigo, de sua discussão e redação e da revisão do texto. Odete Messa Torres participou da revisão bibliográfica, de discussões e revisão do texto. Thaís Maranhão fez a revisão final do manuscrito.

\section{Referências}

1. Portaria $n^{\circ} 2.761$, de 19 de Novembro de 2013. Institui a Política Nacional de Educação Popular em Saúde no âmbito do Sistema Único de Saúde (PNEPS-SUS). Diário Oficial da União. 20 Nov 2013.

2. Minayo MCS. O desafio do conhecimento: pesquisa qualitativa em saúde. 12a ed. São Paulo: Hucitec; 2010.

3. Gil AC. Como elaborar projetos de pesquisa. São Paulo: Atlas; 2002.

4. Laville C, Dionne J. A construção do saber: manual de metodologia da pesquisa em ciências humanas. Monteiro H, Serrineri F, tradutor. Belo Horizonte: Ed. UFMG; 1999.

5. Laperrièrre $\mathrm{H}$. Inovação metodológica: experimentando a educação libertadora em saúde. Saude Transf Soc [Internet]. 2010 [acesso 2012 Nov 10]; 1(1):3-8. Disponível em: http:// periodicos.incubadora.ufsc.br/index.php/saudeetransformacao/article/view/421/480

6. Cassen B. Uma virada política e cultural. In: Cattani AD, organizador. Fórum Social Mundial: a construção de um mundo melhor. Porto Alegre: UFRGS; 2001. p.15-8.

7. Fórum Social Mundial. Carta de Princípios do FSM. Porto Alegre: Fórum Social Mundial; 2001 [Internet] [acesso 2012 Out 5]. Disponível em: http://www.forumsocialmundial.org. $\mathrm{br} /$ main.php?id_menu $=4 \& \mathrm{~cd}$ _language $=1$

8. Santos BS. O Fórum Social Mundial: manual de uso. São Paulo: Cortez; 2005.

9. Grzybowski C. Sim, um outro mundo é possível. In: Cattani AD, organizador. Fórum Social Mundial: a construção de um mundo melhor. Porto Alegre: UFRGS; 2001. p.19-23.

10. Fischer NB, coordenador. Acampamento Intercontinental da Juventude experiência de uma nova geração política e integração sul-americana: caracterização de situações-tipo e organizações juvenis [Internet]. Porto Alegre: Ibase; 2007. [acesso 2012 Out 5]. Disponível em: http://www.ibase.br/pt/wp-content/uploads/2011/06/juv-acampamento-int-da-juv.pdf

11. Sader E. A nova toupeira: os caminhos da esquerda latino-americana. São Paulo: Boitempo; 2009.

12. Ministério da Saúde. Secretaria de Gestão do Trabalho e da Educação na Saúde. Departamento de Gestão da Educação na Saúde. EducarSUS: notas sobre o desempenho do Departamento de Gestão da Educação na Saúde, período de janeiro 2003 a janeiro de 2004. Brasília, DF: MS; 2004. 
13. Portaria $n^{\circ} 198 / G M$, de 13 de fevereiro de 2004. Institui a Política Nacional de Educação Permanente em Saúde como estratégia do Sistema Único de Saúde para formação e o desenvolvimento de trabalhadores para o setor e dá outras providências. Brasília: MS; 2004.

14. Revista POLI. Educação popular em saúde. Poli Saude Educ Trab [Internet]. 2009 [acesso 2012 Dez 20]; 11(8):25-6. Disponível em: http://www.epsjv.fiocruz.br/upload/ EdicoesRevistaPoli/R10.pdf

15. Aneps. O caminho das águas em 2003. In: Relatório do $1^{\circ}$ Encontro Nacional da Articulação Nacional de Movimentos e Práticas de Educação Popular em Saúde. Braślia: ANEPS; 2005.

16. Maranhão T. Vivências e estágios na realidade do Sistema Único de Saúde: um "garimpo" bibliográfico. RECIIS Rev Eletr Comum Inf Inov Saude [Internet]. 2013 [acesso 2013 Dez 30]; 7(4):[14p]. Disponível em: http://www.reciis.icict.fiocruz.br/index.php/ reciis/article/view/862.

17. Torres O. Os estágios de vivência no Sistema Único de Saúde do Brasil: caracterizando a participação estudantil. RECIIS Rev Eletr Comum Inf Inov Saude [Internet]. 2013 [acesso 2013 Dez 30]; 7(4):[7p]. Disponível em: http://www.reciis.icict.fiocruz.br/index.php/ reciis/article/view/860.

18. Freire P. Pedagogia da autonomia: saberes necessários à prática educativa. 5a ed. São Paulo: Paz e Terra; 1996.

19. Bonetti OP, Chagas RA, Siqueira TCA. A educação popular em saúde na gestão participativa do SUS: construindo uma política. In: Ministério da Saúde. Secretaria de Gestão Estratégica e Participativa. Departamento de Apoio à Gestão Estratégica e Participativa. II Caderno de educação popular e saúde. Brasília (DF): MS; 2014. p. 16-24.

20. Oliveira MW. Apresentação - Educação nas práticas e nas pesquisas em saúde: contribuições e tensões propiciadas pela educação popular. Cad CEDES. 2009; 29(79):297-306.

21. Acampamento Intercontinental da Juventude. Projeto da comissão de saúde do $5^{a}$ AlJ. Porto Alegre [Internet]. 2004. [acesso 2014 Fev 25]; Disponível em: http://Iproweb. procempa.com.br/pmpa/prefpoa/acampamentofsm/default.php?reg $=5 \&$ p_secao $=27$.

22. Fórum Social Mundial. Vídeo Espiral Saúde. Comissão de Saúde do $5^{\circ}$ Acampamento Intercontinental da Juventude. Porto Alegre; 2005.

23. Fórum Social Mundial. Vídeo Fórum Social Mundial Belém do Pará. Belém; 2009.

24. Santos BS. A filosofia à venda, a douta ignorância a aposta de Pascal. Rev Crit Cienc Soc [Internet]. 2008 [acesso 2012 Ago 5]; 80:11-43. Disponível em: http://rccs.revues.org/

25. Vasconcelos E. Educação popular e a atenção à saúde da família. 2a ed. São Paulo: Hucitec; 2001.

26. Valla VV, Stotz EN, organizadores. Participação popular, educação e saúde: teoria e prática. Rio de Janeiro: Relume-Dumará; 1993.

27. Ribeiro M. Movimento camponês, trabalho e educação: liberdade, autonomia, emancipação: princípios/fins da formação humana. São Paulo: Expressão Popular; 2010.

28. Stotz E. Os desafios para o SUS e a Educação Popular: uma análise baseada na dialética da satisfação das necessidades de saúde. In: Brasil, Ministério da Saúde. Cadernos de Textos VERSUS. Brasília: MS; 2004. p. 286-301.

29. Pedrosa JIS. Cultura popular e identificação comunitária: práticas populares no cuidado à saúde. In: Martins CM, Stauffer $A$, organizadores. Educação em Saúde. Rio de Janeiro: EPSJV, Fiocruz; 2007. p. 71-100. 
Maranhão T, Bonetti OP, Daron VLP, Torres OM. Espacios de Salud y Cultura: la experiencia del Forum Social Mundial a las Carpas de Educación Popular en Salud. Interface (Botucatu). 2014;18 Supl 2: $\quad-1186$

Buscando identificar posibles contribuciones al campo de la salud colectiva, el artículo analiza los Espacios de Salud y Cultura realizados en los Fórums Sociales Mundiales en Brasil. Es una investigación cualitativa, de abordaje descriptivo, usando investigación documental, analizando documentos, informes, videos y notas en diario de campo. Los resultados señalan que los Espacio de Salud y Cultura innovaron al aproximar a diversos actores de la salud colectiva, articulados al Movimiento de Educación Popular en Salud, trabajadores de la salud, gestores y movimientos de juventud. La Educación popular se señala como referencia político-metodológica de formulación de los espacios que potenciaron la construcción de red multicultural con propuesta de nuevas formas de producir salud. El "Espacio Che" se firma como fuente de inspiración para las Carpas Paulo Freire, realizadas en eventos del área, congresos científicos, encuentros y seminarios.

Palabras clave: Educación Popular en Salud. Participación comunitaria. Salud Colectiva.

ESPAGO DE SAÚdE E CULTURA ERNESTO CHE gUEVARA
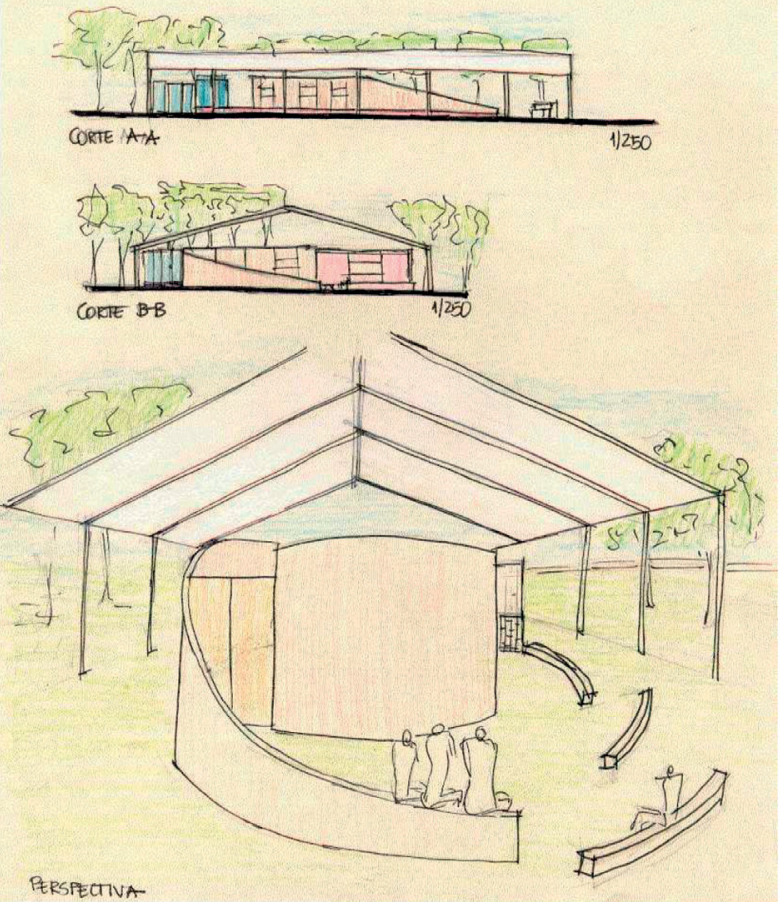

ESPAGO DE SAÚdE E cultura ERNESTO GHe gueVARA

SALA DE RECUPERACANO

fremḱcir VERPE

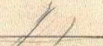

COzINHA

Depósino

CAVETRO

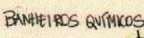
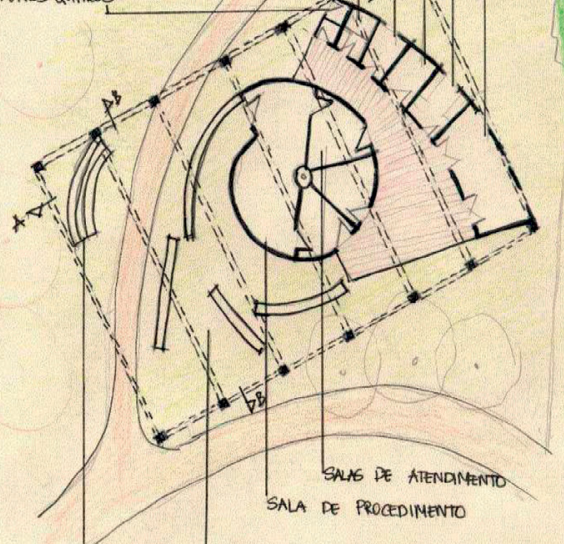

1 ESPAGOS DE PEBATES

espago pe ativipape

(AXÖN10)

Planta baIxa

ESAAL: 1/250

ÁREA DA LONA - $600 \mathrm{~m}^{2}$

ÁREA construía $-160 \mathrm{~m}^{2}$ 